\title{
Idiopathic full thickness macular hole: natural history and pathogenesis
}

\author{
Eric Ezra
}

Although full thickness macular holes (FTMH) were originally described in the last century, in relation to trauma, ${ }^{1-3}$ inflammation, and myopia, ${ }^{23}$ more recent clinical studies have shown that the vast majority are idiopathic $^{4-16}$ and occur with a prevalence of 1/3300 usually in the 6 th and 7 th decades of life..$^{10}$ Many clinical studies have implicated vitreous traction as the cause of idiopathic FTMH formation and it is now widely accepted that traction at the level of the vitreofoveal interface is the underlying mechanism.

Recent work by Kelly and Wendel ${ }^{17}{ }^{18}$ and others ${ }^{19-28}$ has shown that surgical intervention in the form of vitrectomy, cortical vitreous peeling, and gas tamponade is beneficial in the majority of eyes with FTMH in promoting anatomical closure and foveal reapposition with subsequent visual improvement. In addition, these studies have proposed rigorous face down posturing in the postoperative period as an important factor in achieving improved anatomical results. In the light of the implications of surgical intervention and prolonged face down posturing for elderly patients, the natural history of FTMH has assumed great importance, in particular with respect to fellow eye involvement. The purpose of this review is to summarise the natural history, clinical staging, and pathogenesis of idiopathic FTMH.

\section{Natural history and clinical staging}

A number of studies in the 1970 s and 1980 s attempted to define the clinical characteristics and progression of macular holes. These were difficult to interpret owing to lack of consistency in the definitions used by investigators. ${ }^{9-12}$ In particular, studies investigating the nature of the "prehole" lesion proved controversial.

Morgan and Schatz ${ }^{12}$ suggested that involutional thinning resulted in a depressed central area at the fovea which represented the prehole lesion, while others proposed that a foveal cyst ${ }^{1012}{ }_{13}$ occurred before hole formation. Several underlying mechanisms were implicated by these investigators, including degenerative macular thinning, degeneration of a macular cyst, intrinsic retinal pigment epithelium (RPE) disease, systemic vascular disorders, and hormonal influences. ${ }^{8-13}$ These early studies were retrospective in nature and consisted of lesions examined and defined by different clinicians. It was Gass and Johnson ${ }^{15}{ }^{16}$ who described the yellow spot and ring as the prehole lesion, and the systematic clinical staging and evolution of idiopathic FTMH, based on detailed observation and follow up. They proposed that focal shrinkage of the cortical vitreous in the area of the fovea resulted in tangential tractional forces acting on the fovea. Their classification, with its subsequent revision, is that which is now most commonly used by clinicians and will now be described in detail.
THE ORIGINAL GASS CLASSIFICATION ${ }^{15} 16$

Stage 1-Foveolar detachment

This is also termed an "impending hole" and is characterised by progressive loss of the foveal depression, associated with the appearance of initially a yellow spot of approximately $100-150 \mu \mathrm{m}$ at the fovea (stage $1 \mathrm{a}$ ), later enlarging to a yellow ring (stage $1 \mathrm{~b}$ ). These changes were attributed to contraction of the prefoveal vitreous cortex with centripetally directed tangential force, leading to anterior displacement of the foveolar retina and greater visibility of the centrifugally displaced xanthophyll. In stage 1 lesions, the posterior vitreous cortex is attached and the retinal surface is intact without any evidence of hole or subretinal fluid cuff. The visual acuity at this stage is often reasonably good (20/20-20/60 $)^{151629}$ and blurring and metamorphopsia are the primary complaints. These symptoms are the rule not the exception when a patient presents with involvement of the fellow eye but may be unnoticed in the initial eye, particularly if this is the non-dominant eye.

\section{Stage 2-Early FTMH}

Further traction results in the formation of a foveal hole or dehiscence associated with a cuff of subretinal fluid. At this stage, the posterior cortical vitreous is still attached at the fovea and, in many cases, radial tractional striae may be visible around the edges of the hole at the level of the inner retina and internal limiting membrane. In addition, intraretinal cystoid spaces appear around the edges of the hole. The visual acuity usually deteriorates to a level of 20/40-20/100 1516 and metamorphopsia increases. Two configurations may occur at stage 2 :

(a) Centric: The full thickness tear begins at the centre of the fovea (umbo dehiscence) and expands in a symmetric fashion.

(b) Pericentric: A full thickness tear arises at an eccentric position in the fovea and extends in a "can opener" fashion to form a crescentic hole progressing to a "horseshoe" shaped hole and eventually, when the can opener is complete, to a round hole with a fully detached operculum of tissue suspended on the posterior vitreous cortex in the prefoveal plane. This configuration is typical in the majority of stage 2 FTMH (80-90\%).

Stage 3-Fully developed FTMH without posterior vitreous detachment

With further enlargement of the hole, vitreofoveal separation occurs at the macula. The localised separation of the vitreous cortex is usually only detected because of the presence of the operculum suspended on it lying a short distance (between 100 and $500 \mu \mathrm{m}$ ) anterior to the retinal plane. The fully detached operculum, particularly in cases with more widespread vitreofoveal separation, becomes mobile and this may be detected with eye movements. Further enlargement of the hole was attributed by 
Gass to passive forces resulting from elastic tissue forces within the retina. Stage 3 holes usually measure more than $350 \mu \mathrm{m}$ and may occasionally reach a diameter of greater than $500 \mu \mathrm{m}$. In addition, as the hole enlarges, discrete white deposits appear on the surface of the RPE at the base of the hole, which represent nodular proliferations of RPE cells. In more long standing cases, a pigmented demarcation line at the level of the RPE may be seen surrounding the cuff of fluid and diminution of the striae and cystic changes may occur. Stage 3 holes are usually associated with acuity levels of 20/60-20/200, ${ }^{15}{ }^{16}$ prominent metamorphopsia, and on occasions a pericentral positive scotoma.

\section{Stage 4-FTMH with posterior vitreous detachment}

In about $20 \%$ of cases, a full posterior vitreous detachment (PVD) occurs with the presence of a Weiss ring. The operculum can often be seen on the mobile posterior vitreous face in the vitreous cavity. In the majority of cases, little or no further enlargement of the hole occurs thereafter with little significant functional deterioration.

THE REVISED GASS CLASSIFICATION

In 1995 Gass reappraised his theory of macular hole formation. ${ }^{30}$ Initially, he had suggested that vitrectomy and peeling of the premacular posterior vitreous cortex might prevent stage 1 lesions from progressing. ${ }^{15} 16$ Although early surgical studies suggested that this was indeed the case, ${ }^{31-33}$ a randomised study subsequently proved inconclusive, when it was terminated before sufficient numbers had been recruited to reach statistical significance between the treatment and observation groups. ${ }^{34-36}$ Attention was then focused on whether vitreous peeling in established FTMH might result in hole closure and visual improvement. Kelly and Wendel ${ }^{17}{ }^{18}$ and others ${ }^{19-28}$ have since demonstrated that the majority of established FTMH may be closed surgically using vitrectomy, posterior cortical vitreous peeling, and long acting intraocular gas tamponade, and that the majority of eyes demonstrate significant visual improvement. Indeed, in many cases, visual acuity may improve to near normal levels of between 20/20 and $20 / 60 .^{17-28}$

In the light of these results, in his recent reappraised theory, ${ }^{30}$ Gass suggested that the majority of FTMH arise from an umbo dehiscence without loss of foveal tissue. $\mathrm{He}$ hypothesised that the stage $1 \mathrm{~b}$ lesion is caused by centrifugal displacement of xanthophyll associated with foveolar detachment, and following a retinal dehiscence at the umbo, by passive enlargement of the "occult" hole beneath the semiopaque, contracted vitreous cortex bridging the edges of the hole. Thus, at this stage, biomicroscopy cannot differentiate between an impending hole and an occult hole. Subsequently, a tear occurs in the contracted vitreous cortex overlying the occult hole, over the edge (pericentric/eccentric stage 2) of the occult hole and the hole becomes visible on biomicroscopy as a stage 2 lesion. Enlargement of the eccentric tear in a can opener fashion occurs to form a "pseudo-operculum" composed of vitreous collagen, glial tissue but no photoreceptors. In some cases, rapid and complete vitreofoveal separation occurs and the umbo dehiscence becomes immediately visible on biomicroscopy as a centric stage 2 lesion. With vitreofoveal separation, the FTMH evolves into a stage 3 and eventually a stage 4 hole when a full PVD develops.

PROGRESSION AND TIME COURSE

The progression from stage 1 to stage 2 and from stage 2 to stage 3 usually takes several weeks or months, although in some cases the lesion may remain static without progression at any of the stages described. In most patients it is difficult to establish with any certainty the exact duration of the lesion, as many stage 1 and some stage 2 lesions are asymptomatic, particularly if occurring in the first eye of the patient. In fact, very few lesions present at stage 1 and most patients only experience symptoms and attend for examination when a full thickness defect has become established at the fovea. Most patients with a first eye lesion usually only notice symptoms by coincidence, either after happening to cover the normal fellow eye, or when attending for routine refraction. In contrast, patients with a second eye lesion will often give an accurate account of the onset of symptoms and the duration of the lesion may be determined with greater certainty.

Johnson and Gass ${ }^{16}$ and Kokame et $a l^{29}$ observed that approximately $66 \%$ of stage 1 lesions progressed to FTMH, somewhat higher estimates compared with those of $37 \%$ by Akiba et $a l^{37}$ and $10.5 \%$ by Guyer et al. ${ }^{38}$ Hikichi et al noted that approximately $67 \%$ of stage 2 holes progressed to stage 3 and approximately $30 \%$ to stage $4 .^{39}$ More recently, Kim et al reported the results of a randomised trial which included an observation arm for stage 2 holes. ${ }^{40}$ They found a $55 \%$ progression rate to stage 3 for centric stage 2 holes, compared with $100 \%$ for pericentric (can opener) holes, with an overall progression rate of all stage 2 holes to either stage 3 or 4 of $74 \%$.

SPONTANEOUS ARREST AND CLOSURE OF MACULAR HOLE LESIONS

It is well recognised that $30-50 \%$ of stage $1 \mathrm{a}$ and $1 \mathrm{~b}$ lesions will arrest or resolve spontaneously often with resolution symptoms in some eyes..$^{15} 162936$ In such cases, arrest usually occurs following vitreofoveal separation and a good visual acuity is a favourable prognostic indicator. ${ }^{29}$

Gass has described the clinical features of arrested lesions. ${ }^{15}$ The fovea may have an entirely normal contour $(\mathrm{Ar}-\mathrm{A} / \mathrm{B})$, or may demonstrate a residual small inner lamellar defect (Ar-C) or larger inner lamellar defect (Ar-D) often with an operculum on the separated vitreous face. In such cases, patients may notice the operculum as a small dark mobile object in the visual axis but the visual acuity is usually normal or near normal. In some patients, the operculum may cast a shadow onto the fovea, during slit lamp examination, which may be mistaken for a FTMH.

Spontaneous closure may also occur in a stage 2 or 3 lesion, although this is relatively rare, occurring in less than $10 \%$ of cases..$^{15} 16404$ Again this is usually associated with vitreofoveal separation in stage 2 holes and further vitreofoveal separation or a full PVD in stage 3 holes. The closed hole may demonstrate a virtually normal foveal reflex or a lamellar defect as described above and the visual acuity may recover to the 20/20-20/60 level. In the majority of cases, vitreofoveal separation with an operculum is seen and only a minority will develop a full PVD.

EXAMINATION AND DIAGNOSIS

Although impending holes and FTMHs may be confused with a number of other foveal and macular lesions, ${ }^{15} 164243$ careful slit lamp biomicroscopy is usually sufficient to establish the diagnosis in the majority of cases. In particular, fundus contact lens examination should be performed in all cases where doubt exists. The Watzke-Allen test ${ }^{44}$ is also extremely useful in differentiating FTMHs from other lesions. In this test, a very narrow slit beam is projected with a 90 or 78 dioptre lens onto the fovea and the patient is asked to describe the line. Most patients with a stage 3 FTMH report a break in the central portion of the line (Watzke-Allen positive), whereas those with small holes (with a relatively intact foveal photoreceptor population) or other lesions associated with metamorphopsia may report 
"thinning" (Watzke-Allen negative). A more reliable test may be performed by projecting a $50 \mu \mathrm{m} \mathrm{HeNe} \mathrm{laser} \mathrm{spot}$ onto the centre of the suspected FTMH; the patient with a FTMH will not perceive the spot. ${ }^{15} 16$

Fundus fluorescein angiography is rarely necessary in FTMH and in the vast majority, careful clinical examination may establish the diagnosis and stage. The angiographic findings at the various stages of macular hole development have been well described. . $^{5-14-16262740}$ In impending FTMH, early faint central focal hyperfluorescence is seen at the fovea in some cases, while in others a normal angiogram may occur. In stage 2 holes, the central early hyperfluorescence is usually more pronounced and fades during the later stages of the run; however, in some cases no hyperfluorescence is observed. Thus, fluorescein angiography cannot differentiate with any certainty between stage 1 and 2 lesions and clinical examination is often more reliable. In stage 3 and 4 lesions, the hyperfluorescence is more obvious and is frequently associated with changes at the RPE level which may also be seen biomicroscopically. In these lesions, the cuff of subretinal fluid surrounding the hole may appear either as a hyperfluorescent or hypofluorescent ring around the central area of hyperfluorescence. Other techniques such as confocal scanning laser ophthalmoscopy and microperimetry, ${ }^{45-48}$ autofluorescence, ${ }^{49}$ and retinal thickness analysis ${ }^{50}$ have also been used to assess macular holes. Although these are rarely feasible in the routine clinical setting because they require a level of technical expertise, they provide promising objective methods for analysing the morphological and functional aspects of macular holes, particularly before and after surgery . Optical coherence tomography (OCT), a relatively new technique, has also been used to allow detailed cross sectional examination of macular holes and may be effective in distinguishing them from other lesions where doubt exists. ${ }^{51}$

\section{Incidence of macular hole in fellow eyes}

Although FTMH is an important cause of central visual loss with a prevalence of 3.3 per 1000 , the majority of patients have unilateral involvement at presentation and are able to continue with good visual function from the fellow eye. Thus, the risk to the fellow eye is an important factor for both patients and clinicians in determining whether surgical treatment of the first eye is pursued. In particular, the risks of surgery, anaesthesia, and the postoperative posturing regimens have to be considered very carefully in older patients, especially if the risk to the normal fellow eye is low. In assessing the risk to a fellow eye without a hole, two important factors have to be considered: (1) the presence of a predisposing foveal lesion such as an impending hole indicates a higher risk of progression to FTMH in the region of $40-60 \%$; and (2) the presence of a PVD, as indicated by a Weis ring, is associated with an extremely low risk of progression to FTMH of less than $1 \%$.

Although a number of studies, mostly retrospective, ${ }^{4-69-11} 133852-54$ have reported on the incidence of FTMH in fellow eyes, ranging between $0 \%$ and $29 \%$, the data have been difficult to interpret as some studies have not differentiated between normal fellow eyes and fellow eyes with possible predisposing lesions such as macular cysts and impending holes, while others have not differentiated between normal fellow eyes with and without a PVD. In a retrospective study of 69 patients, Aaberg et at found that $7 \%$ of patients had bilateral FTMH at presentation, while a further $11 \%$ developed a hole in the fellow eye during a mean follow up of 19 months, although in this study, no differentiation was made between fellow eyes with a predisposing foveal lesion and fellow eyes with a normal fovea. In another retrospective study, Bronstein et $a t^{33}$ reported a $7 \%$ incidence of bilaterality on presentation and a $12 \%$ incidence of FTMH in initially normal fellow eyes over a mean follow up of 57 months, while in contrast McDonnell et al, ${ }^{10}$ in a similar analysis, found a $2 \%$ bilaterality at presentation, with a $0 \%$ progression in initially normal fellow eyes at a mean follow up of 27 months. Neither of these studies, however, differentiated between initially normal fellow eyes with and without a PVD at presentation. Trempe et $a l,{ }^{13}$ in a retrospective study of 49 eyes, found a bilaterality of $3 \%$ at presentation, and on subsequent mean follow up of 47 months, $28 \%$ of fellow eyes without a PVD at presentation developed a FTMH compared with $0 \%$ of fellow eyes with a PVD at presentation. However, this study did not differentiate between fellow eyes with and without predisposing foveal lesions and it is likely that the higher progression rate in fellow eyes was biased by the inclusion of fellow eyes with impending holes at presentation.

In a prospective 5 year cohort study of 114 normal fellow eyes without a PVD, conducted at Moorfields Eye Hospital, we found an incidence of $7.5 \%$ at 18 months and $15.6 \%$ at 5 years, ${ }^{55}$ as determined by Kaplan-Meier analysis. This was somewhat higher than the risk reported by Fisher $e t a \bar{l}^{6}$ in a smaller prospective study of 30 normal eyes without a PVD at presentation, where an incidence of progression of $3.5 \%$ occurred over the study period which was less than 3 years. However, the latter is probably an underestimate and is difficult to interpret because the authors excluded a number of patients owing to lack of follow up, without Kaplan-Meier analysis, and did not specify the exact follow up period for this group. Their study also reported on a cohort of 16 normal fellow eyes with a pre-existing PVD at presentation. In this group, $0 \%$ of eyes went on to develop a FTMH. The Eye Disease Case-Control Study group reported a cohort of 198 patients with macular holes and normal fellow eyes examined at baseline, of whom $122(71 \%)$ were available for follow up, with a rate of fellow eye involvement of $4.3 \%$ at 3 years and $6.5 \%$ at 5 years. No details were available on the presence or absence of a PVD in fellow eyes at baseline. ${ }^{57}$

Other studies have also examined the value of electrodiagnostic tests in predicting which normal fellow eyes will eventually develop FTMH. In one study, focal electroretinography (FERG) testing showed that fellow eyes which later develop FTMH may have reduced FERG responses. ${ }^{58}$ In our prospective fellow eye study outlined above, we demonstrated elevated tritan thresholds during colour contrast sensitivity (CCS) testing of apparently normal fellow eyes but the threshold was not predictive of which eyes later developed holes. ${ }^{55}$ Although these data suggest that even an apparently normal fovea may in fact be subject to some degree of traction resulting in cone misalignment and malfunction before symptoms or signs of foveal traction become apparent, electrodiagnostic techniques have not proved to be particularly useful or feasible in general ophthalmic practice, in predicting fellow eyes at risk.

Thus, from the data available to date, it appears that in patients with a unilateral FTMH, the 5 year risk to a normal fellow eye without a PVD is in the region of $10-20 \%$, while the risk is extremely small, probably less than $1 \%$, if a PVD is present. The overall risk to a normal fellow eye is in the region of $5-10 \%$ over 5 years. The risk to a fellow eye with an impending hole is much higher and is in the region of about $40-60 \%$.

\section{Pathogenesis of FTMH formation and histopathological studies}

Several hypotheses for the pathogenesis of FTMH have been suggested including cystic foveal degeneration, 


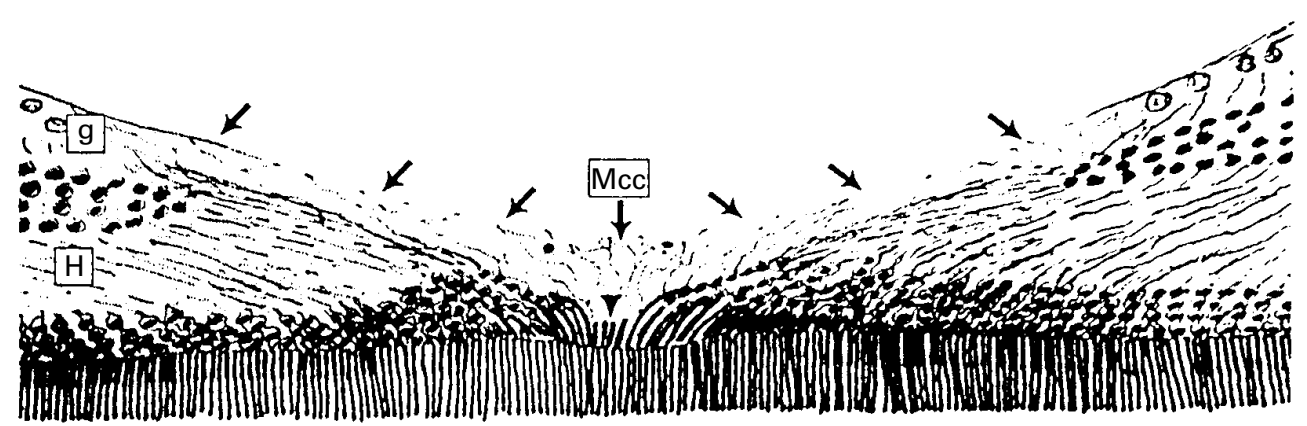

Figure 1 Schematic representation of the normal human fovea centralis from Gass ${ }^{62}$ based on the histological findings of Yamada ${ }^{63}$ and Hogan et al. ${ }^{64}$ The Muller cell cone $(M c c)$ is shown with its base forming the internal limiting membrane (arrows) and its truncated apex forming the outer limiting membrane at the umbo (arrowhead). The Henle nerve fibre layer $(H)$ and the foveal extremety of the ganglion cell layer $(g)$ are also demonstrated. (From Gass FDM, "The Muller cell cone. An overlooked part of the normal fovea”. Arch Ophthalmol 1999;117:821-3. Copyrighted 1999, American Medical Association.)

systemic vascular disease, and mechanical forces due to fluid motion and countercurrents in the premacular bursa during ocular movements. ${ }^{4-16}$ However, it is now generally accepted that idiopathic FTMH are caused by vitreofoveal traction. This is consistent with the presence of radial striae in the majority of cases during the early stages, the presence and progression of the yellow spot and ring during stage 1, a relatively high incidence of PVD following the development of FTMH, and the negligible risk of hole formation in eyes with a pre-existing PVD. Although some authors have suggested that anterior vitreofoveal traction occurs as a result of shrinkage of vitreous collagen fibres extending from the fovea to the anterior vitreous, ${ }^{59}$ it seems unlikely that this mechanism accounts for the majority of cases, because anterior displacement of the foveal rim forward of the retinal surface is rarely seen and where it does occur, it is associated with an incomplete PVD at the macula and is termed vitreomacular traction syndrome.

Gass $^{1516}$ and Guyer and colleagues ${ }^{6061}$ have suggested that FTMHs arise from local tangential vitreofoveal traction due to either shrinkage of the prefoveal vitreous cortex caused by cellular remodelling or by contraction of a thin glial membrane on the retinal surface. The presence of a glial membrane has been emphasised by Gass ${ }^{30}$ who has proposed that in the "can opener" stage 2 lesion, a glial membrane covers the surface of an "occult" hole and progression of the can opener represents an extending dehiscence in the membrane itself, finally resulting in a free "pseudo-operculum", comprising exclusively glial tissue, suspended on the vitreous cortex after vitreofoveal separation has occurred. The position of a "pseudo-operculum" suspended on the vitreous cortex anterior to the retinal plane is a cosequence of the anterior vectoral component of a tangential force at the surface of the fovea.

More recently, Gass has emphasised the importance of the foveal Muller cell "cone", ${ }^{62}$ originally described by Yamada $^{63}$ and Hogan et $a l^{64}$ in histological studies of the normal human foveola (Fig 1). These studies showed the foveola to be composed of an inverted cone of Muller glia with a truncated apex up to the external limiting membrane (ELM). Between the apex and the ELM were radially oriented inner cone segments radiating towards the beginning of the outer nuclear layer of cone nuclei. The base of the cone formed the umbo and extended into the clivus in the perifoveolar region. The internal limiting membrane (ILM) lining the base of the cone was extremely thin $(10-20 \mathrm{~nm})$ compared with the peripheral fovea. The sides of the cone were apposed to radiating inner segments centrally and cone nuclei in the outer nuclear layer more peripherally towards the perifoveolar region.
Gass has suggested that the Muller cell cone has three important roles in idiopathic FTMH formation. ${ }^{62}$ (1) The glia contain concentrated superficial xanthophyll which migrates centrifugally during the formation of a FTMH and may be seen biomicroscopically as a yellow spot or ring. The presence of xanthophyll with opercula supports this hypothesis. (2) The Muller cone provides structural support for the radiating inner cone segments at the foveola and its disruption may lead to damage and atrophy of the cone cells in this area. (3) The Muller cells within the cone invade the prefoveolar vitreous cortex and initiate cellular remodelling and contraction, resulting in tangetial forces on the foveola, centrifugal migration of photoreceptors and xanthophyll, further disruption of the Muller cell cone, and eventually an umbo dehiscence. Furthermore, a potential cleavage plane may exist between the truncated apex of the cone and the cone elements at the umbo which may result in schitic changes at the foveola during hole formation.

Although previous histological data from light and electron microscopic analysis of prefoveal vitreous cortex, removed at the time of surgery for impending holes, have confirmed the presence of glial cells at this early stage of hole development, ${ }^{65}{ }^{66}$ it remains unclear whether these glia initiate foveolar traction by cortical vitreous remodelling or whether they represent an attempted healing response to mechanically induced damage at the fovea due to vitreous traction. ${ }^{306768}$ A number of observations indicate that epiretinal glial proliferation at the fovea occurs commonly even in apparently normal asymptomatic eyes: (1) Foos ${ }^{69} 70$ has demonstrated at post mortem the presence of a preretinal glial membrane in up to $30 \%$ of apparently normal eyes without PVD where no retinal distortion is present; (2) the majority of eyes $(70 \%)$ with holes do not appear to have significant visible membrane around the edge of the hole ${ }^{16}$; (3) only about $50 \%$ of holes are found to have glial proliferation at surgery, and in the vast majority this is of a very friable and nebulous nature rather than the typical confluent ERM found in macular pucker. ${ }^{71}$

Histopathological studies on the ultrastructure of stage 3 macular hole opercula have provided further clues to the pathophysiological mechanisms in FTMH formation. Overall, all opercula (100\%) studied so far have been found to contain Muller cells and/or fibrous astrocytes, $61-100 \%$ have had identifiable ILM fragments and about $40-50 \%$ have contained cone photoreceptors ranging from a few scattered cones to those with densely packed cone photoreceptors. ${ }^{626768}$

It is difficult on histological grounds to determine whether glial cells within an operculum are avulsed epiretinal glia within a membrane (that is, a pseudo-operculum), 


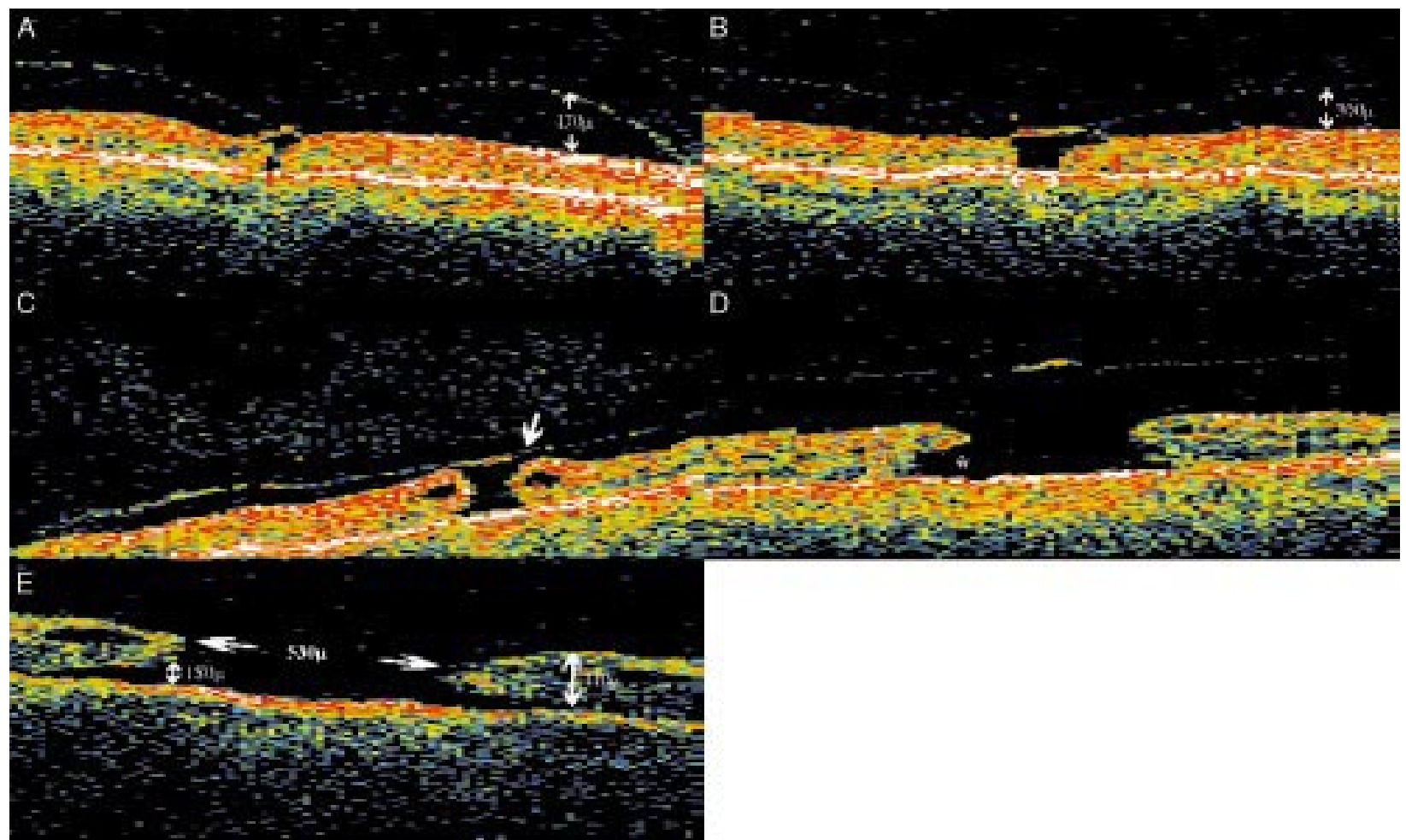

Figure 2 Evolution of idiopathic FTMHs on OCT. A 69 year old female with a long standing FTMH in the first eye and a 2 month history of central visual loss (acuity 6/12) and metamorphopsia in the fellow eye caused by a stage 1a lesion. OCT examination $(A)$ revealed a central foveal detachment and a high reflectance interface in the preretinal plane which is thought to represent the posterior vitreous cortex, partially detached at the macula but remaining tethered to the central fovea. (B) Two months later a stage $1 \mathrm{~b}$ lesion was noted on funduscopy and OCT revealed a more extensive foveal detachment. (C) At 4 months after the onset of symptoms, she had developed a stage 2 lesion with the acuity dropping to 6/24. The OCT confirms the presence of a pericentric full thickness break (arrow) and the early formation of an operculum. Cystic spaces are present at the edges of the hole. The patient elected to undergo surgical treatment at this stage. (D) An OCT of a stage 3 lesion in a 70 year old woman, showing a FTMH (380 $\mu \mathrm{m})$ with vitreomacular separation and an operculum suspended on the posterior vitreous face. A prominent subretinal fluid cuff is visible (asterisk). (E) A stage 4 lesion in a 65 year old man. Note the extensive subretinal fluid cuff and the prominent cystoid spaces at the level of the inner plexiform layer at the edges of the hole.

avulsed inner retinal glia (that is, a true operculum), or both. However, the presence of fragments of internal limiting membrane in some opercula $(61-100 \%)^{67}{ }^{68}$ indicates that a significant number of opercula containing only glia contain avulsed glial tissue from the inner fovea and are also "true opercula". The lack of indentifiable ILM in some opercula suggests that these may represent avulsed epiretinal glia rather than inner retinal glia and that in these cases "in situ" disruption of the Muller cell cone may indeed be sufficient to cause an umbo dehiscence. ${ }^{62}$

The variation in cone photoreceptor density in opercula (40-50\% contain photoreceptors) probably reflects the amount of foveal tissue avulsed during hole formation. In fact, clinicopathological correlation on a small number of opercula from stage 3 holes, excised during vitrectomy, has shown that the anatomical success rate following surgery is lower in cases with opercula containing a high cone density ${ }^{68}$ This may reflect the larger tissue defect in these cases, where effective postoperative glial repair is less likely to occur. However, it is difficult to draw firm conclusions from these data because of the small numbers of cases involved and clearly further clinicopathological correlations of macular hole opercula would be valuable but diffcult owing to the small size of the opercula. Histological postmortem studies on surgically closed FTMH have also shown that the residual foveal defect sealed or "plugged" by reparative glia after successful surgery may range from 16 to $250 \mu \mathrm{m}^{72-74}$ consistent with a spectrum of pathology.

Optical coherence tomography (OCT) and recent hypotheses of the pathogenesis of FTMH formation Recent studies of the early stages of FTMH using OCT $^{51756}$ have shown that vitreomacular separation may actually occur around the posterior pole before hole formation rather than after hole formation as suggested by Gass. These observations have suggested that an incomplete posterior pole vitreous cortical separation occurs with residual tethering at the fovea and optic disc, and assumes

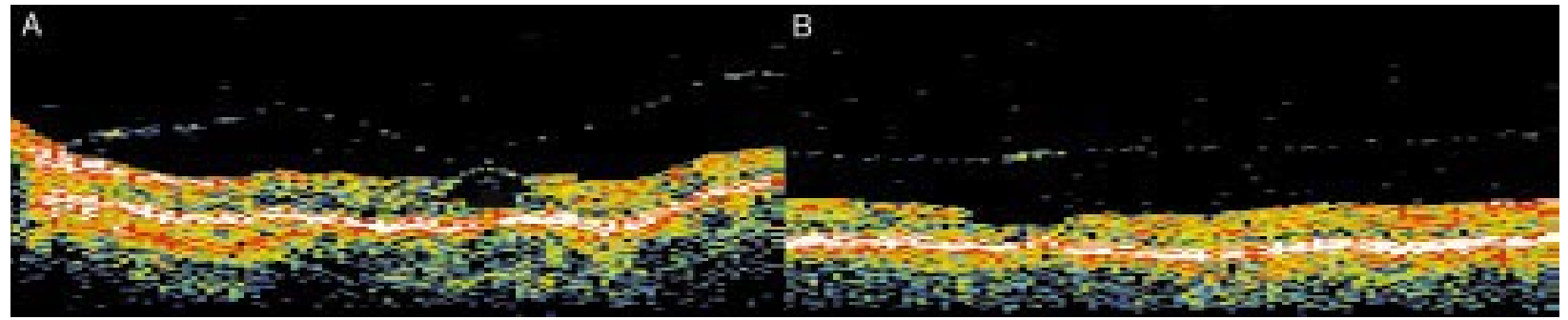

Figure 3 Spontaneous arrest of a stage 1 lesion. (A) OCT of the fellow eye of a 64 year old woman with a stage 1 a lesion on funduscopy and acuity of 6/9. The lesion was observed and 2 months later she reported an improvement in her metamorphopsia. Funduscopy revealed a reattached fovea with an inner lamellar defect. A free operculum was present in the preretinal plane with vitreomacular separation but otherwise attached vitreous. OCT (B) confirmed the clinical findings and no residual vitreofoveal traction. The visual acuity remained at 6/9 throughout follow up. 


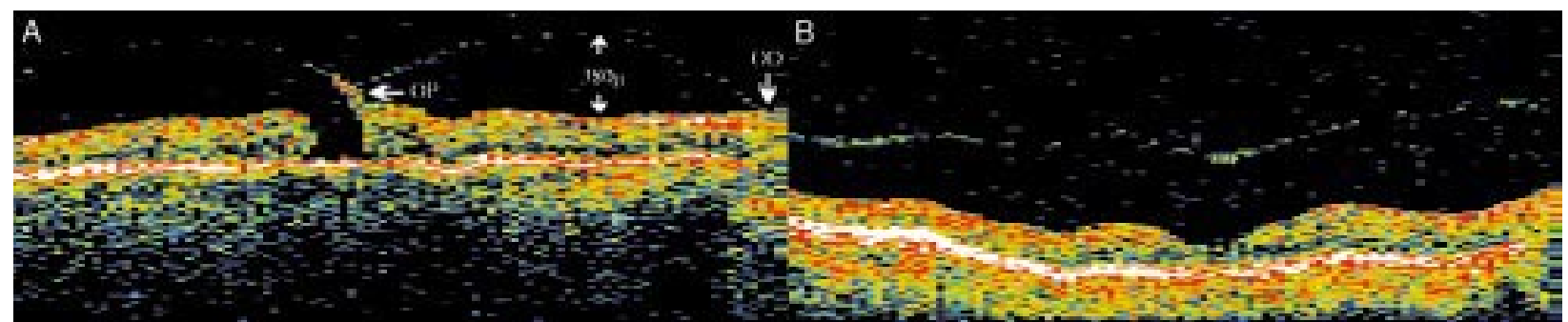

Figure 4 Spontaneous arrest and closure of a stage 2 lesion. (A) OCT of the first eye of a 56 year old female who presented with a stage 2 "can opener" lesion and a visual acuity of 6/36. Three months later she reported an improvement in the visual acuity (6/12) and funduscopy revealed a normal foveal reflex with vitreomacular separation and a free floating operculum. OCT (B) showed a relatively normal foveal contour, vitreomacular separation with an operculum, and no residual vitreofoveal traction.

a "trampoline" configuration (Figs 2-4). ${ }^{76-78}$ This anatomical configuration may be seen in stage 1 lesions where no vitreous separation can be detected clinically by biomicroscopy and would be consistent with the observations on postmortem eyes, using electron microscopy, of firm vitreoretinal adhesions at the fovea which are not present elsewhere. ${ }^{79}{ }^{80}$ Mechanical forces transmitted through the vitreous with eye movements and possibly contraction of the vitreous face between the fovea and the disc and between the fovea and the residual peripheral extramacular temporal attachment, would result in an oblique vector force with both anterior and tangential vectoral components, ${ }^{81}$ leading to avulsion of foveal tissue and complete posterior pole vitreous separation.

As further traction occurs, a full thickness tear is seen through the fovea resulting in the formation of a stage 2 FTMH with focal tethering of the posterior vitreous cortex to the operculum. Eventually, the operculum is completely avulsed from the fovea resulting in a stage $3 \mathrm{FTMH}$ characterised by complete vitreomacular separation and release of the tractional forces on the fovea. Thus the operculum would come to lie anterior to the preretinal plane and this is the earliest time at which vitreous separation over the macula can be detected with biomicroscopy.

In a recent OCT study Gaudric et $a l^{76}$ confirmed the "trampoline" configuration of the vitreous cortex in the majority of eyes with FTMH. They also demonstrated that some impending holes are characterised by foveal cyst formation, with the presence of a cystic cavity beneath the elevated retina and retinal tissue beneath the cystic space. The potential cleavage plane in the foveola between the inner retinal Muller glia and the laterally displaced cone inner segments was confirmed. They concluded that in a significant number of holes, localised vitreofoveal traction results in the formation of a foveal cyst, through the cleavage plane, which later becomes deroofed. The avulsed roof, comprising glial cells only, would form a glial operculum, while the uncovered floor of the cyst, comprising cone nuclei, would degenerate resulting in a FTMH. These findings indicate that FTMH may arise from different precursor lesions, as a full thickness foveal detachment, as described by Gass, or as a foveal cyst. It is possible to speculate that in FTMH arising from cysts, the operculum would comprise glia only, while in those preceded by a cyst, the operculum would contain some photoreceptor elements.

The OCT findings suggest that FTMHs develop in a situation where there is failure of normal age related separation of the vitreous cortex from the posterior pole as a result of an abnormally tenacious attachment to the fovea. The residual attachment at the foveal centre, in the trampoline configuration, may act as a focal point where mechanical forces are transmitted from the vitreous to the foveolar surface leading to foveal traction. Clearly, further studies are required to confirm these findings and to determine the validity of these concepts; in particular, detailed natural history studies correlating the clinical progression of FTMHs with the OCT findings. Clinicopathological correlation between biomicroscopic and OCT findings and the cone density in opercula may shed further light on the precise mechanisms leading to hole formation. Such studies will help to define the risk characteristics for progression in early lesions and risk factors for visual outcome after surgery.

ERIC EZRA

Vitreoretinal Unit, Moorfields Eye Hospital, City Road, London EC1V 2PD, UK

Correspondence to: ericezra@hotmail.com

1 Knapp H. Uber isolorite zerreissungen der aderhaut in folge von traumen auf dem augopfel. Arch Augenheilkd 1869;1:6-12.

2 Collins ET. Unusual changes to the macular region. Trans Ophthalmol Soc UK 1900;20:196-7.

3 Noyes HD. Detachment of the macula with laceration of the macula lutea. Trans Am Ophthalmol Soc 1971;1:128-34.

4 Yaoeda H. Clinical observation on macular hole. Acta Soc Ophthalmol fpn 1967;71:1723-36.

5 Aaberg TM, Blair CJ, Gass JDM. Macular holes. Am f Ophthalmol 1970;69: 555-62.

6 Aaberg TM. Macular holes: a review. Surv Ophthalmol 1970;15:139-62. 7 Gass JDM. Stereoscopic atlas of macular diseases: diagnosis and treatment. St Louis: CV Mosby, 1970:195-9.

8 Margherio RR, Schepens CL. Macular breaks: I. Diagnosis, etiology, and observations. Am F Ophthalmol 1972;74:219-32.

9 James M, Fenman SS. Macular holes. Graefes Arch Klin Exp Ophthalmol 1980;215:59-63.

10 McDonnell PJ, Fine SL, Hillis AI. Clinical features of idiopathic macular cysts and holes. Am $\mathcal{F}$ Ophthalmol 1982;93:777-86.

11 Morgan CM, Schatz H. Idiopathic macular holes. Am f Ophthalmol 1985;99:437-44

12 Morgan CM, Schatz H. Involutional macular thinning: a pre-macular hole condition. Ophthalmology 1986;93:153-61.

13 Trempe CL, Weiter JJ, Furukawa H. Fellow eyes in cases of macular hole: biomicroscopic study of the vitreous. Arch Ophthalmol 1986;104:93-5.

14 Gass JDM. Stereoscopic atlas of macular diseases: diagnosis and treatment. St Louis: CV Mosby, 1987:684-93.

15 Gass JDM. Idiopathic senile macular hole:its early stages and development. Arch Ophthalmol 1988;106:629-39.

16 Johnson RN, Gass JDM. Idiopathic macular holes. Observations, stages of formation and implications for surgical intervention. Ophthalmology 1988; 95:917-24.

17 Kelly NE, Wendel RT. Vitreous surgery for idiopathic macular holes: results of a pilot study. Arch Ophthalmol 1991;190:654-9.

18 Wendel RT, Patel AC, Kelly NE, et al. Vitreous surgery for macular holes. Ophthalmology 1993;100:1671-6.

19 Glaser BM, Michels RG, Kupperman BD, et al. The effects of pars plana vitrectomy and transforming growth factor-beta 2 for the treatment of fullthickness macular holes:a prospective randomized study. Ophthalmology 1992;99:1162-73.

20 Lansing MB, Glaser BM, Liss $\mathrm{H}$, et al. The effect of pars plana vitrectomy and transforming growth factor-beta 2 without epiretinal membrane peeling on full-thickness macular holes. Ophthalmology 1993;100:868-71.

21 Orrellana J, Lieberman RM. Stage III macular hole surgery. Br 7 Ophthalmol 1993;77:555-8.

22 Smiddy WE, Glaser BM, Thompson JT, et al. Transforming growth factorbeta 2 significantly enhances the ability to flatten the rim of subretinal fluid surrounding macular holes: preliminary anatomic results of a multicentre prospective randomized study. Retina 1993;13:296-301.

23 Ryan EH, Gilbert HD. Results of surgical treatment of recent onset full-thickness idiopathic macular holes. Arch Ophthalmol 1994;112:154553.

24 Ruby AJ, Williams DF, Grand MG, et al. Pars plana vitrectomy for treatment of stage 2 macular holes. Arch Ophthalmol 1994;112:359-64.

25 Wells JA, Gregor ZJ. Surgical treatment of full-thickness macular holes using autologous serum. Eye 1996;10:593-9.

26 Kim JW, Freeman WR, Azen SP, et al. Prospective randomised trial of vitrectomy for stage 2 macular holes. Am $\mathcal{f}$ Ophthalmol 1996;121:605-14.

27 Freeman WR, Azen SP, Kim JW, et al. Vitrectomy for the treatment of fullthickness stage 3 or 4 macular holes. Results of a multicentre randomised controlled trial. Arch Ophthalmol 1997;115:11-22. 
28 Ezra E, Aylward WG, Gregor ZJ. Membranectomy and autologous serum for the retreatment of full-thickness macular holes. Arch Ophthalmol 11997; for the retreat

29 Kokame GT, de Bustros S, The Vitrectomy for Prevention of Macular Hole Study Group. Visual acuity as a prognostic indicator in stage 1 macular holes. Am f Ophthalmol 1995;119:112-14.

30 Gass JDM. Reappraisal of biomicroscopic classification of stages of development of a macular hole. Am f Ophthalmol 1995;119:752-9.

31 Smiddy WE, Michels RG, Glaser BM, et al. Vitrectomy for impending macular holes. Am $\mathcal{F}$ Ophthalmol 1988;105:371-6.

32 Jost BF, Hutton WL, Fullet DG, et al. Vitrectomy in eyes at risk of macular hole formation. Ophthalmology 1990;97:843-7.

33 Margherio RR, Trese MT, Margherio AR, et al. Surgical management of vitreomacular traction syndromes. Ophthalmology 1989;96:1437-45.

34 De Bustros S. Early stages of macular holes:to treat or not to treat. Arch Ophthalmol 1990;108:979-82.

35 De Bustros S. Vitrectomy for prevention of macular hole study. Arch Ophthalmol 1991;109:1057.

36 De Bustros S, The Vitrectomy for Prevention of Macular Hole Study Group. Vitrectomy for the prevention of macular holes: results of a randomized clinical trial. Ophthalmology 1994;101:1055-60.

37 Akiba J, Kakehashi A, Arzabe CW, et al. Risk of developing a macular hole. Arch Ophthalmol 1990;108:1088-90.

38 Guyer Dr, de Bustros S, Diener-West M, et al. The natural history of idiopathic macular holes and cysts. Arch Ophthalmol 1992;110:1264-8

39 Hikichi T, Yoshida A, Akiba J, et al. Prognosis of stage 2 macular holes. Am f Ophthalmol 1995;119:571-5.

40 Kim JW, Freeman WR, El-Haig W, et al. Baseline characteristics, natural history, and risk factors to progression in eyes with stage 2 macular holes. Results from a prospective randomized clinical trial. Ophthalmology 1995;102:1818-29.

41 Kakehashi A, Schepens CL, Akiba J, et al. Spontaneous resolution of foveal detachments and macular breaks. Am f Ophthalmol 1995;120:767-75.

42 Gass JDM, Joondeph BC. Observations concerning patients with suspected impending macular holes. Am f Ophthalmol 1990;109:638-46.

43 Smiddy WE, Gass JDM. Masquerades of macular holes. Ophthalmic Surg 1995;26:16-24.

44 Watzke RC, Allen L. Subjective slit lamp beam sign for macular disease. Am f Ophthalmol 1969;68:449-53.

45 Weinberger D, Stiebel H, Gaton H, et al. Three dimensional measurements of idiopathic macular holes using scanning laser tomograph. Ophthalmology 1995; 102:1445-9.

46 Hudson C, Charles SJ, Flanagan JG, et al. Objective morphological assessment of macular hole surgery by scanning laser tomography. Br f Ophthalmol 1997;81:107-16.

47 Beausencourt E, Elsner AE, Hartnett ME, et al. Quantitative analysis of macular holes with scanning laser tomography. Ophthalmology 1997;104: 2018-29.

48 Guez JE, Le Gargasson JF, Massin P, et al. Functional assessment of macular hole surgery by scanning laser ophthalmoscopy. Ophthalmology 1998;105:694-9

49 Ruckmann A, Fitzke F, Gregor ZJ. Fundus autofluorescence in patients with macular holes imaged with a laser scanning ophthalmoscope. Br f Ophthalmol 1998;82:346-51.

50 Asrani S, Zeimer R, Goldberg MF, et al. Serial optical sectioning of macular holes at different stages of development. Ophthalmology 1998;105:66-77.

51 Hee MR, Puliafito CA, Wong C, et al. Optical coherence tomography of macular holes. Ophthalmology 1995;102:748-56.

52 Croll LJ, Croll M. Hole in the macula. Am f Ophthalmol 1950;33:248-53.

53 Bronstein MA, Trempe CL, Freeman HM. Fellow eyes with macular holes. Bronstein MA, Trempe CL, Freema

54 Lewis ML, Cohen SM, Smiddy WE, et al. Bilaterality of idiopathic macular holes. Graefes Arch Clin Exp Ophthalmol 1996;234:241-5.

55 Ezra E, Wells JA, Gray RH, et al. Incidence of Idiopathic full-thickness macular holes in fellow eyes. A five year prospective natural history study. Ophthalmology 1998;105:353-9.

56 Fisher YL, Slakter JS, Yannuzzi LA, et al. A prospective natural history study and kinetic ultrasound evaluation of idiopathic macular holes. Ophthalmology 1994;101:5-11.
57 Chew EY, Sperduto RD, Hiller R, et al. Clinical course of macular holes. The Eye Disease Case-Control Study. Arch Ophthalmol 1999;117:242-6.

58 Birch DG, Jost BF, Fish GE. The focal electroretinogram in fellow eyes of patients with idiopathic macular holes. Arch Ophthalmol 1988;106:155863.

59 Avila MP, Jalkh AE, Murakami K, et al. Biomicroscopic study of the vitreous in macular breaks. Ophthalmology 1983;90:1277-83.

60 Guyer DR, Green RW, de Bustros S, et al. Histopathological features of idiopathic macular holes and cysts. Ophthalmology 1990;97:1045-51.

61 Guyer DR, Green RW. Idiopathic macular holes and precursor lesions. In: Franklin RM, ed. Proceedings of the symposium on retina and vitreous. New York: Kugler Publications, 1993:135-62.

62 Gass JDM. Muller cell cone, an overlookedpart of the anatomy of the fovea centralis. Hypotheses concerning its role in the pathogenesis of macular hole and foveomacular retinoschisis. Arch Ophthalmol 1999;117:821-3.

63 Yamada E. Some structural features of the fovea centralis in the human retina. Arch Ophthalmol 1969;82:152-9.

64 Hogan MJ, Alvarado JA, Weddell JE. Histology of the human eye. An atlas and textbook. Philadelphia: WB Saunders, 1971:492-7.

65 Campochiaro PA, Van Niel E, Vinores SA. Immunocytochemical labeling of cells in cortical vitreous from patients with premacular hole lesions. Arch Ophthalmol 1992;110:371-7.

66 Smiddy WE, Michels RG, de Bustros S, et al. Histopathology of tissue removed during vitrectomy for impending idiopathic macular holes. Am $\mathcal{F}$ Ophthalmol 1989;108:360-4.

67 Madreperla SA, McCuen BW II, Hickingbotham D, et al. Clinicopathologic correlation of surgically removed macular hole opercula. Am $\mathcal{F}$ Ophthalmol 1995;120:197-207.

68 Ezra E, Munro PMG, Charteris DG, et al. Macular hole opercula. Arch Ophthalmol 1997;115:1381-7.

69 Roth AM, Foos RY. Surface wrinkling retinopathy in eyes enucleated at autopsy. Trans Am Acad Ophthalmol Otolaryngol 1971;75:1047-58.

70 Foos RY. Surface wrinkling retinopathy. In: Freeman HM, Hirose T, Schepens CL, eds. Vitreous surgery and advances in fundus diagnosis and treatment. New York: Appleton, 1977:23-8.

71 Wendel RT, Patel AC. Full-thickness macular hole. In: Bovino JA, ed. Macular surgery. Norwalk, CT: Appleton-Lange, 1994:49-60.

72 Funata M, Wendel RT, de la Cruz Z, et al. Clinicopathological study of bilateral macular holes treated with pars plana vitrectomy and gas tamponade. Retina 1992;12:289-98.

73 Madreperla SA, Geiger GL, Funata M, et al. Clinicopathological correlation of a macular hole treated by cortical vitreous peeling and gas tamponade. Ophthalmology 1994:101:682-6.

74 Rosa RH Jr, Glaser BM, de la Cruz Z, et al. Clinicopathologic correlation of an untreated macular hole and a macular hole treated by vitrectomy, transforming growth factor-beta 2, and gas tamponade. Am $\mathcal{F}$ Ophthalmol 1996; 122:853-63.

75 Puliafito CA, Hee MR, Schuman JS, et al. Optical coherence tomography of ocular diseases. Thorofare, NJ: Slack Inc, 1996.

76 Gaudric A, Haouchine B, Massin P, et al. Macular hole formation. New data provided by optical coherence tomography. Arch Ophthalmol 1999;117: 744-51.

77 Mori K, Abe T, Yoneya S. Dome-shaped detachment of premacular vitreous cortex in macular hole development. Ophthalmic Surg Lasers 2000;31:2039.

78 Gallemore RP, Jumper JM, McCuen BW, et al. Diagnosis of vitreoretinal adhesions in macular disease with optical coherence tomography. Retina 2000;20:115-20.

79 Foos RY. Vitreoretinal junction; topographical variations. Invest Ophthalmol 1972;11:801-8.

80 Kishi S, Demaria C, Shimizu K. Vitreous cortex remnants at the fovea after spontaneous vitreous detachment. Int Ophthalmol 1986;9:253-60.

81 Chauhan DS, Antcliff RJ, Rai PA, et al. Papillofoveal traction in macular hole formation: the role of optical coherence tomography. Arch Ophthalmol 2000;118:32-8. 